\title{
Smoking-associated fibrosis and pulmonary asbestosis
}

\author{
This article was published in the following Dove Press journal: \\ International Journal of COPD \\ 19 December 2014 \\ Number of times this article has been viewed
}

\author{
Jacob R Bledsoe' \\ David C Christiani \\ Richard L Kradin ${ }^{1,2}$ \\ 'Department of Pathology, \\ ${ }^{2}$ Department of Medicine, \\ Massachusetts General Hospital, \\ Boston, MA, USA
}

Correspondence: Richard L Kradin Department of Pathology, Massachusetts General Hospital, Warren Building 253,

55 Fruit Street, Boston, MA 02I I4, USA

Tel + I 6177269029

Fax + I 6177267474

Email rkradin@partners.org

\begin{abstract}
The diagnosis of pulmonary asbestosis is most often established based on clinical criteria and has both clinical and legal implications. Unfortunately, one of the confounding features in the diagnosis may be a history of cigarette abuse, which can produce interstitial opacities on chest imaging as well as diffusion defects on pulmonary function testing, criteria that are used in the diagnosis of pulmonary asbestosis. The objective of the present study was to evaluate the correlation of radiographically detected pulmonary fibrosis with fibrosis established histopathologically as attributable to asbestos, in a cohort referred for diagnosis of an asbestos-related malignancy in the context of litigation. We examined the slides of 186 cases with reported asbestos exposure, referred in consultation for asbestos-related malignancy and the presence of pulmonary fibrosis. Sixty-five cases had what was judged to be adequate tissue sampling for histopathologic evaluation of asbestosis as well as an existing radiologic assessment of pulmonary fibrosis by B-reader report. Of 24 cases judged to have asbestosis radiographically, which had sufficient tissue for pathologic examination, six showed asbestosis histopathologically. The remaining 18 cases (mean smoking history of 53 pack-years) showed interstitial fibrosis that was judged to be most consistent with smoking-associated pulmonary fibrosis. We conclude that the clinical diagnosis of mild asbestosis cannot be reliably distinguished from interstitial fibrosis in heavy smokers.
\end{abstract}

Keywords: asbestos, smoking, pulmonary fibrosis

\section{Introduction}

The diagnosis of pulmonary asbestosis is most often established on clinical grounds. This is in part due to the high prevalence of mild disease that is encountered in current practice, which typically does not warrant an invasive diagnosis. According to both the American Thoracic Society (ATS) 1986 and 2004 statements on benign asbestosrelated disorders, radiographic findings play an important role, along with exposure history, in establishing a diagnosis of pulmonary asbestosis. ${ }^{1,2}$ The criteria endorsed by the ATS for a radiographic diagnosis of asbestosis are based on the International Labor Organization (ILO) Classification of Pneumoconioses. ${ }^{1,3}$ Within the United States, a certification program conducted by the National Institute for Occupational Safety and Health qualifies so called "B readers" to interpret conventional chest radiographs. $\mathrm{B}$ readers classify opacities in chest radiographs according to the ILO system on the basis of size, concentration, location, and shape. ${ }^{3}$ The concentration of small opacities, or profusion, is classified on a 12-point scale based on comparison to standard radiographs and grouping into one of four categories ranging from 0 (absence of small opacities, or fewer opacities than category 1) to 3. A two-digit profusion score is rendered, with the first digit representing the favored interpretation and the second digit representing an alternative category, if considered. Therefore, the profusion score takes the format of "-/-", with values ranging from $0 /-$ to $3 /+.^{3}$ 
In 2004, the ATS issued a revised Consensus Statement on the Diagnosis and Initial Management of Nonmalignant Diseases Related to Asbestos. ${ }^{2}$ Recognizing that profusion is a continuous function, the revised statement suggested that:

A critical distinction is made between films that are sugges-

tive but not presumptively diagnostic $(0 / 1)$ and those that are

presumptively diagnostic but not unequivocal $(1 / 0){ }^{2}$

On this basis, the suggested radiographic criteria for the clinical diagnosis of pulmonary asbestosis based on the ILO system were revised from a threshold profusion of $1 / 1$ to $1 / 0$, with the corollary that computerized tomography (CT) and high resolution CT might enhance sensitivity. However, CT scans cannot necessarily distinguish asbestosis from other forms of interstitial fibrosis, and in such cases only an examination of lung tissue can establish the diagnosis of asbestosis with accuracy.,5

The 2004 ATS statement acknowledged that smokers without fibrogenic dust exposure can show irregular opacities on chest film, but determined that profusion is rarely as high as 1/0 in such cases, and that smoking alone does not generally result in a chest film with the characteristics of asbestosis. ${ }^{2}$ However, the literature currently suggests that small opacities are often present in smokers, and recent findings have demonstrated that smoking-associated fibrosis is similar in both its radiographic and histological appearance to that seen in the lungs of patients with mild asbestosis. ${ }^{6-8}$

The aim of the present study was to examine the correlation of radiologic and pathologic diagnoses of asbestosis in cases referred in the context of litigation for pulmonary malignancy, and to explore the potential role of smokingassociated fibrosis in the discordant cases. We examined 186 cases referred to the practice of one of our group (RLK, Massachusetts General Hospital, Boston, MA, USA) for consultation with respect to the presence of an asbestos-related disease - in virtually all cases an intrathoracic malignancy. In this select population, we found that the prevalence of asbestosis as judged by clinical exposure with appropriate latency and ILO B-readings of $\geq 1 / 0$ tended to overestimate the presence of asbestosis established by histopathology, and that the majority of cases showed histologic evidence that was most consistent with smoking-associated fibrosis.

\section{Materials and methods}

We examined the medical records, B-reader reports, and pathology materials of 186 consecutive consultation cases received from throughout the United States for the purpose of assessing the presence of asbestos-related disease including malignancy and pulmonary fibrosis. One hundred and seventy-eight cases showed evidence of malignancy. Exposure data such as profession, years at the workplace, and smoking histories were based on self-report. No information on specific product exposures was available. Data from all subjects were de-identified at the beginning of the study.

Evaluation of chest radiographs had been performed prior to the time of consult, with multiple ILO-certified B readers evaluating each case as part of the litigation process. The $\mathrm{B}$ readers were aware of the asbestos exposure status and the medical-legal implications of the cases, and no radiographs from unexposed subjects were interspersed as controls. Independent review of the radiographs was not performed by the authors. B-readers' reports were available for 183 patients. Detailed pulmonary function tests (PFTs) were available in 47 (25\%) of the cases.

Slides were cut and stained by the referring institutions and sent for review. Five $\mu \mathrm{m}$ hematoxylin and eosin (HE) sections were examined by a pulmonary pathologist (RLK) for the presence of malignancy and for evidence of non-tumorous parenchymal lung disease. Sections of lung uninvolved by and distant from tumor were examined for evidence of interstitial lung disease. The number of sections of uninvolved lung varied from one, in the minority of cases, to eight depending on the size of the resection specimen. At least one Prussian blue-stained section, which accentuates the presence of asbestos bodies, was examined in all cases. When possible, as in pneumonectomy and lobectomy specimens, at least one central and one peripheral section per lobe were evaluated. Within the lung, the location sampled (eg, the specific lobe) was dictated by the site of the tumor and extent of the resection. The authors were unblinded to asbestos exposure, smoking status, and corresponding B-reading interpretation at the time of histopathologic evaluation, and no unexposed controls were used. Transbronchial biopsies were not included in this analysis.

The microscopic diagnosis of asbestosis was based on the identification of one or more asbestos bodies in the setting of interstitial fibrosis of the pattern typically seen in asbestos-related pulmonary fibrosis, in accordance with the patterns and diagnostic criteria reported by Roggli et $\mathrm{al}^{5}$ and Craighead et $\mathrm{al}^{9}$ and consistent with the consensus report on Helsinki Criteria requiring the identification of asbestos bodies to make a definitive pathologic diagnosis (Figure 1). ${ }^{10,11}$ The pattern of fibrosis characteristically observed in asbestosis has been described as early bronchiolar wall and peribronchiolar fibrosis, with progressive extension first into peribronchiolar alveoli and then into alveoli further from the bronchiole, ultimately resulting in fibrosis bridging adjacent respiratory bronchioles and, in late stages, honeycomb fibrosis. ${ }^{5}$ Tissue digestion and fiber 


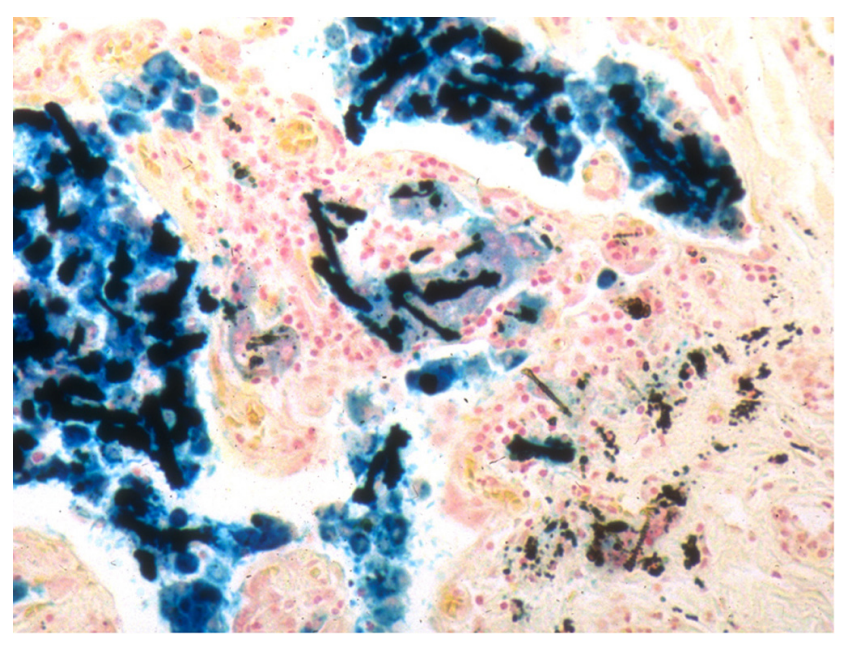

Figure I Asbestos bodies.

Notes: Prussian blue-stained section from a subject with asbestos exposure and interstitial fibrosis. Original magnification $\times 200$.

analysis methods were not performed in this study as lung tissue was not available.

Criteria used for the diagnosis of smoking-associated interstitial fibrosis included a history of heavy smoking ( $>20$ pack-years) in addition to interstitial fibrosis of the pattern seen in smoking-associated fibrosis associated with the presence of emphysema or respiratory bronchiolitis. In these cases, interstitial fibrosis was not limited to peribronchiolar zones but more extensively involved the alveolar walls, often in a patchy distribution and subpleurally, as has been described previously. ${ }^{7,12,13}$ Specific pathologic features lending evidence to a smoking-related fibrosis included the characteristic paucicellular alveolar septal thickening and

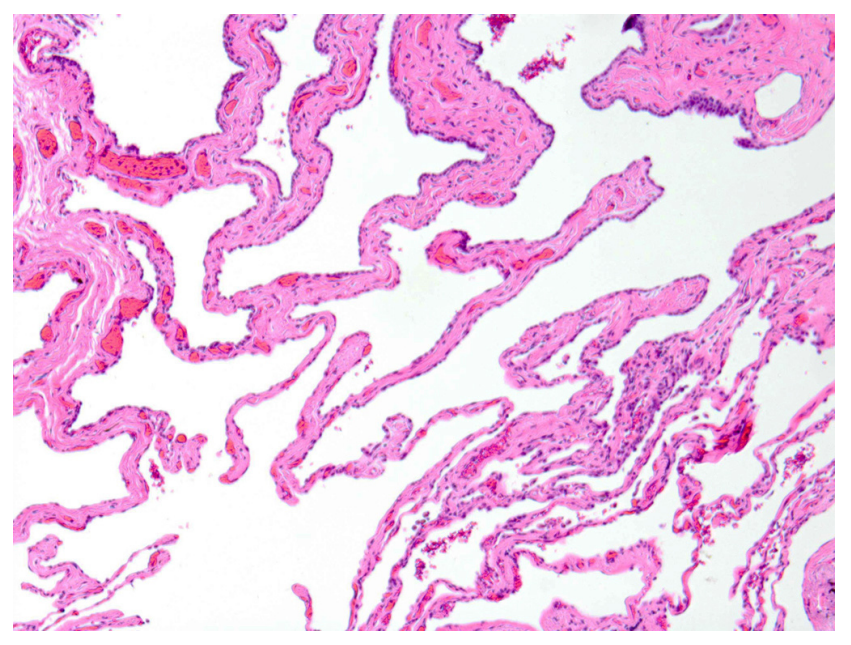

Figure 2 Smoking-associated interstitial fibrosis.

Notes: Hematoxylin and eosin stained section. Note the widening of alveolar septae by dense eosinophilic fibrosis with a paucity of inflammatory cells. Original magnification $\times 200$. eosinophilic "ropey collagen" appearance of alveolar wall fibrosis (Figure 2) ${ }^{7,12}$

\section{Results}

Data from 174 men and 12 women were examined. The average age was 68 years. Table 1 shows the sources of asbestos exposure, which were primarily occupational. Of the women, all but one reported secondary exposure to asbestos through the laundering of their husband's work clothes. The average duration of putative asbestos exposure was 27 years $(\mathrm{N}=174)$. A history of cigarette smoking was present in 126 of 143 patients (88\%) with data available, and the average cumulative dosage of cigarette smoke was 46 pack-years. A histologically proven pulmonary malignancy was present in 178 patients; 101 (54\%) patients had a primary lung cancer and 77 (41\%) had malignant mesothelioma (Table 2). In eight cases, no evidence of malignancy was identified.

The clinical diagnosis of asbestosis was based on exposure status, clinical findings, and radiologic evidence of interstitial lung disease. A radiographic diagnosis of asbestosis was established in 62 (34\%) of 183 cases in which B-reader reports were available, based on the present ILO standard of profusion of $1 / 0$ or greater (either $1 / 0$ or $1 / 1$ in all cases). Of the 62 cases with ILO profusion $\geq 1 / 0,51$ had data on smoking status: 50 were smokers (mean pack-years: 46 ) and the one non-smoker did have histologic evidence of asbestosis (see below). Pleural plaques were identified by radiology in 82 (44\%) of cases. For patients with available PFTs, 20 (42.5\%) showed an obstructive pattern, $15(32 \%)$ showed a restrictive pattern, and $12(25.5 \%)$ were normal, using the National Health and Nutrition Examination Survey III (NHANES III) reference values. ${ }^{14}$ No mixed PFT patterns were seen.

Only the 67 cases with sections showing pulmonary fibrosis unrelated to and distant from tumor were regarded as sufficient for evaluation. Of these, 24 cases were diagnosed as positive for asbestosis based on exposure and radiographic findings, two cases did not have corresponding B-reader reports, and 41 cases were considered negative for asbestosis on clinical/radiological grounds (Figure 3).

Resections of lung judged sufficient to establish a histopathological diagnosis of asbestosis were present in eight of the total 67 cases (12\%). In the six cases with histologically proven asbestosis as well as radiographic evidence of asbestos, all had an ILO profusion of 1/1. Two cases showed histopathologic evidence of asbestosis but an ILO profusion of $<1 / 0$. The remaining 18 cases with $\mathrm{B}$ readings $\geq 1 / 0$ showed scarring in the lung that was characteristic of 
Table I Subjects' profession, duration of asbestos exposure, smoking status, and type of malignancy

\begin{tabular}{|c|c|c|c|c|c|c|c|c|}
\hline Profession & $\mathbf{N}$ & $\begin{array}{l}\text { Mean age } \\
\text { (yrs) }\end{array}$ & $\begin{array}{l}\text { Mean exposure } \\
\text { (yrs) }\end{array}$ & $\begin{array}{l}\text { Exposure } \\
\text { time range* }\end{array}$ & $\begin{array}{l}\text { Smokers } \\
\text { (\%) }\end{array}$ & $\begin{array}{l}\text { Mean pack- } \\
\text { years }\end{array}$ & $\begin{array}{l}\mathbf{N} \text { with lung } \\
\text { cancer (\%) }\end{array}$ & $\begin{array}{l}\mathrm{N} \text { with } \\
\text { mesothelioma (\%) }\end{array}$ \\
\hline Boilermaker & 9 & 70 & 25 & $1936-1988$ & 83 & 44 & $5(56)$ & $3(33)$ \\
\hline Brakes-mechanic & 2 & 60 & 24 & $1943-1999$ & 100 & 35 & $2(100)$ & 0 \\
\hline Bricklayer & 3 & 58 & 30 & $1939-1980$ & 67 & 33 & $2(67)$ & 0 \\
\hline Carpenter & 5 & 69 & 31 & $1936-1989$ & 100 & 59 & $4(80)$ & I (20) \\
\hline Construction & 3 & 67 & 21 & $1949-1986$ & 100 & 30 & $2(67)$ & I (33) \\
\hline Electrician & II & 72 & 30 & |939-199| & 80 & 45 & $7(64)$ & $4(36)$ \\
\hline Insulator & 9 & 72 & 24 & $194 \mid-1996$ & 100 & 26 & $3(33)$ & $5(56)$ \\
\hline Laborer & 26 & 70 & 28 & $1940-1999$ & 90 & 47 & $19(73)$ & $3(12)$ \\
\hline Machinist & 7 & 63 & 22 & $1930-1995$ & 100 & 56 & $4(57)$ & $3(43)$ \\
\hline Mason & 5 & 64 & 24 & $1940-1996$ & 75 & 62 & $4(80)$ & I (20) \\
\hline Mechanic/maintenance & 13 & 63 & 22 & $1936-2000$ & 100 & 43 & $5(38)$ & $8(62)$ \\
\hline Millwright & 4 & 68 & 25 & $1940-1982$ & 100 & 46 & $3(75)$ & I (25) \\
\hline Operator & II & 69 & 34 & $1943-2000$ & 100 & 51 & $9(82)$ & I (9) \\
\hline Plumber/pipefitter & 17 & 68 & 29 & $1936-1999$ & 77 & 47 & $7(4 I)$ & $10(59)$ \\
\hline Shipyard & 17 & 68 & 24 & 1939-2002 & 100 & 46 & $5(29)$ & $12(7 \mid)$ \\
\hline Sheetmetal & 3 & 70 & 21 & $1935-1980$ & 50 & 75 & I (33) & $2(67)$ \\
\hline Steelworker & 2 & 68 & 29 & $1943-1983$ & 100 & 30 & $2(100)$ & 0 \\
\hline Welder & 8 & 69 & 30 & $1943-1993$ & 100 & 55 & $5(63)$ & $3(38)$ \\
\hline Laundry & II & 51 & 18 & $1935-1993$ & 14 & 50 & 0 & II (100) \\
\hline Other & 20 & 72 & 26 & $1947-1986$ & 100 & 47 & $12(60)$ & $8(40)$ \\
\hline Total & 186 & 68 & 27 & $1930-2002$ & 88 & 46 & $101(54)$ & $77(4 I)$ \\
\hline
\end{tabular}

Notes: The percentage of smokers is based on a total of 143 subjects for whom a smoking history was available. *Exposure time range is the range of years in which each group reported asbestos exposure - the vast majority reported significant exposure time before 1975. Totals are indicated in bold font.

Abbreviations: $\mathrm{N}$, number of subjects; yrs, years.

smoking-associated fibrosis, with no microscopic evidence of asbestos bodies (Table 3 ). These cases included 16 with a definite history of smoking (mean pack-years: 53) and two for which no data on smoking status were available but in which histopathologic changes consistent with smoking were seen, specifically emphysema, respiratory bronchiolitis, and paucicellular alveolar wall fibrosis. Comparison of demographic data between those ILO profusion $\geq 1 / 0$ cases with and without histologically established asbestosis were similar (Table 4). A background of emphysema and respiratory bronchiolitis was seen in virtually all smokers with more than 20 pack-year smoking histories.

Table 2 Subtypes of malignancy diagnoses within the cohort

\begin{tabular}{ll}
\hline Malignancy & Number (\%) \\
\hline Lung & \\
Adenocarcinoma & $37(20)$ \\
Squamous cell carcinoma & $22(12)$ \\
Non-small cell lung carcinoma & $20(1 \mathrm{I})$ \\
Small cell carcinoma & $17(9)$ \\
Other & $5(3)$ \\
Mesothelioma & $77(4 \mathrm{I})$ \\
No malignancy & $8(4)$ \\
Total & 186 \\
\hline
\end{tabular}

Notes: "Other" lung malignancies included large cell neuroendocrine carcinoma, carcinoid, and adenosquamous carcinoma. Total number of subjects indicated in bold.

\section{Discussion}

The cases in this series were all referred for consultation with respect to the role of asbestos as a causative agent of lung disease in the context of litigation. All cases had putatively

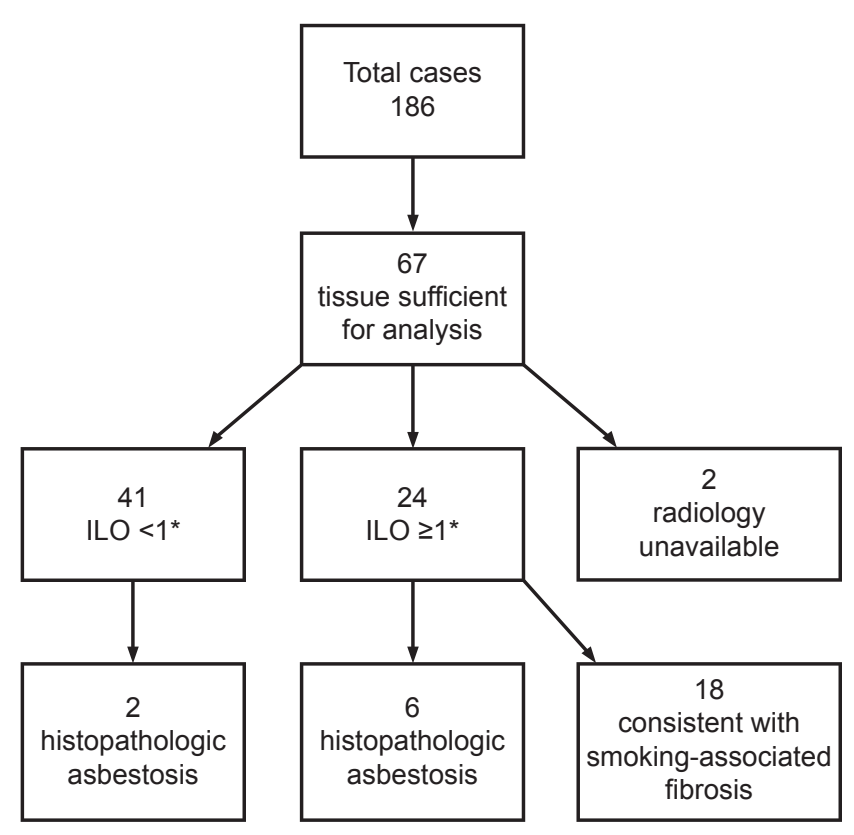

Figure 3 Flow chart showing the breakdown of cases with and without histologic and radiologic evidence of asbestosis and fibrosis. $*<I$ and $\geq I$ refer to ILO profusion. Abbreviation: ILO, International Labor Organization. 
Table 3 Correlation of ILO profusion, histopathologic evidence of asbestosis, and smoking

\begin{tabular}{|c|c|c|c|c|c|c|}
\hline & \multicolumn{5}{|l|}{ ILO profusion } & \multirow[t]{3}{*}{ Total } \\
\hline & \multicolumn{2}{|l|}{ ILO $\geq I$} & \multicolumn{2}{|l|}{ ILO < I } & \multirow[t]{2}{*}{ Unknown } & \\
\hline & $\begin{array}{l}\mathbf{N} \\
\text { (\% smokers) }\end{array}$ & $\begin{array}{l}\text { Smoking status } \\
\text { not available }(\mathbf{N})\end{array}$ & $\begin{array}{l}\mathbf{N} \\
\text { (\% smokers) }\end{array}$ & $\begin{array}{l}\text { Smoking status } \\
\text { not available }(\mathbf{N})\end{array}$ & & \\
\hline Asbestosis & $6(83)$ & 0 & $I(100)$ & 1 & 0 & 8 \\
\hline No asbestosis & $16(100)$ & 2 & $27(89)$ & 12 & 2 & 59 \\
\hline Not evaluable* & $29(100)$ & 9 & $60(80)$ & 20 & I & 119 \\
\hline Total & $51(98)$ & II & $88(83)$ & 33 & 3 & 186 \\
\hline
\end{tabular}

been exposed to asbestos, although the specifics of exposure were often not available beyond a description of the type of work that the individual provided. For this reason, no specific quantitative information with respect to product exposures has been presented. Instead, this study focuses on accuracy of establishing a clinical diagnosis of asbestosis, particularly in the presence of alternative and potentially confounding etiologies of fibrosis such as smoking. We found that a diagnosis of pulmonary asbestosis based on clinical criteria including a $\mathrm{B}$ reading of ILO profusion $\geq 1 / 0$ was present in $34 \%$ of cases, whereas histopathologic evidence of asbestosis was found in only $12 \%$ of cases. A concordant diagnosis of pulmonary asbestosis based on histopathologic criteria was established in $25 \%$ of the 24 cases with ILO profusion $\geq 1 / 0$, with the remainder of cases showing changes judged most consistent with smoking-associated fibrosis. These findings suggest that the radiologic diagnosis of mild asbestosis (eg, close to the recommended cut-off of ILO profusion $\geq 1 / 0$ ) has significant overlap with smoking-associated fibrosis, and cannot be accurately distinguished.

The 2004 ATS statement notes that the risk of developing asbestosis may be increased in smokers due to diminished fiber clearance, and concedes that smoking may produce centrilobular opacifications, but it adopts the position that smoking rarely produces irregular opacities of profusion graded at or above $1 / 0 .{ }^{2}$ However, questions have been raised concerning the confounding role of cigarette smoking on the clinical diagnosis of asbestosis. Studies have suggested that approximately $5 \%$ of smokers show irregular opacities on posterior-anterior chest radiographs, ${ }^{15}$ and have noted that smoking alone can produce changes that mimic the radiographic appearance of pulmonary asbestosis. ${ }^{6,16}$ Similarly, it has been increasingly recognized that cigarette smoking is associated not only with such well-acknowledged pathologies as emphysema and respiratory bronchiolitis, but also appears to predispose to the development of interstitial fibrosis, including idiopathic pulmonary fibrosis. In recent years, it has been noted that subpleural fibrosis with a characteristic histological appearance that can mimic that of asbestosis is likely attributable to cigarette smoking. ${ }^{7,12}$ Katzenstein et al demonstrated that interstitial fibrosis other than well-defined entities such as usual interstitial pneumonitis/idiopathic pulmonary fibrosis and asbestosis, and involving more than $25 \%$ of lung lobectomy slides, was identified in nine of 20 smokers (45\%), but was not seen in three nonsmokers. ${ }^{7}$ Another recent study demonstrated interstitial lung abnormalities in 194 (8\%) of the 2,416 high-resolution CT scans performed on smokers, and concluded that restrictive changes often seen in interstitial lung disease may be offset by the increased total lung capacity associated with emphysema, leading to near-normal pulmonary function tests in some smokers and the possibility of clinical under-recognition of smoking-related changes, including fibrosis. ${ }^{8}$

One prior study examined the relationship between the radiographic and pathologic diagnosis of asbestosis in patients with pulmonary malignancy. They found that in 138 asbestos insulation workers with pathologically confirmed lung cancer, all had histologic interstitial pulmonary fibrosis. ${ }^{17}$

Table 4 Demographics of 24 cases with ILO profusion $\geq I$ and sufficient tissue for histopathologic evaluation

\begin{tabular}{llllll}
\hline $\begin{array}{l}\text { Histologic } \\
\text { diagnosis }\end{array}$ & $\mathbf{N}$ & Average age & $\begin{array}{l}\text { Malel } \\
\text { female }\end{array}$ & $\begin{array}{l}\text { Mean potential years of } \\
\text { asbestos exposure (range) }\end{array}$ & $\begin{array}{l}\text { Mean smokers } \\
\text { pack-years }\end{array}$ \\
\hline Asbestosis & 6 & 72 & $6 / 0$ & $25(14-34)$ & 41 \\
No asbestosis & 18 & 69 & $18 / 0$ & $25(7-40)$ & $100 *$ \\
\hline
\end{tabular}

Note: *Two cases had no available smoking history status but had histopathologic changes consistent with smoking.

Abbreviation: ILO, International Labor Organization. 
In this regard, these findings are similar to ours in that all cases with ILO profusion $\geq 1 / 0$ and adequate pathologic material for evaluation showed interstitial fibrosis. Where the current study differs is in the proportion of cases in which the fibrosis was attributed to asbestos. Such cases were the majority in the prior study by Kipen et $\mathrm{al}^{17}$ but make up the minority in the current study. This difference may be due to a number of factors, including differences in the grading of fibrosis or recognition of smoking-related fibrotic histopathologic changes, which have become better-established only recently.

There is considerable debate over the criteria for the diagnosis of asbestosis, both clinically and histopathologically. Clinically, the diagnosis rests on exposure status, symptomatology, clinical testing, radiology, and exclusion of other potential causes of pulmonary fibrosis. Microscopically, a definitive diagnosis can be made only when asbestos bodies are present along with appropriate fibrosis. ${ }^{5,9}$ The presence of asbestos bodies without fibrosis establishes exposure but is not sufficient for the diagnosis of asbestosis. Furthermore, the absence of asbestos bodies, even if the distinctive pattern of fibrosis is observed in a patient with an exposure history and established clinical diagnosis, precludes the definitive pathologic diagnosis of asbestosis. However, it does not exclude asbestos as the causative agent of the fibrosis, as a number of product exposures, such as Chrysotile, are known to produce fibrosis without significant asbestos body formation. ${ }^{5}$ Therefore, the absence of asbestos bodies does not necessarily diminish the relevance of asbestos exposure in the clinical evaluation of interstitial fibrosis, but the pathologic diagnosis should be based on histologic findings including fibrosis, as well as the identification of the responsible agent. ${ }^{5,18,19}$ Accordingly, it should be noted that in the current study even though the cases with fibrosis and without asbestos bodies had histologic features of smoking-associated fibrosis, the concomitant influence of asbestos exposure cannot be entirely ruled out. Furthermore, the absence of an objective exposure marker for smoking-related disease means that we can depend only on the smoking history, the histopathological appearance of fibrosis, and the absence of asbestos bodies for distinction. Although smoking-associated fibrosis has recently been described, ${ }^{7,12}$ no epidemiological studies have yet been undertaken that definitively prove that smoking is in fact the cause of fibrosis. Detailed ultrastructural examination of lung tissue that might have uncovered the presence of other fibrogenic dusts was undertaken in a preliminary study of three cases of smoking-related fibrosis with no asbestos exposure, and failed to reveal increased asbestos burdens. (Ronald F Dodson, personal communication, 2012).
The present study suffers from various scientific limitations. Firstly, our sample size was limited to 65 cases with both pathologic and radiologic diagnoses and 24 cases with radiology consistent with asbestosis and adequate tissue for histopathologic assessment. Additionally, the study is not prospective, the cases were examined in the context of litigation, and the $\mathrm{B}$ readings were not independently confirmed. Substantial controversy surrounds B readings of chest radiographs in the context of litigation, ${ }^{20}$ and interobserver variability cannot be excluded as an influential factor. Certainly, the possibility of litigation bias must be considered, although the primary investigator was rendering an opinion on behalf of the patient, and if anything, might have been expected to be more biased in favor of the diagnosis of "asbestosis". However, the study does represent a situation that is often faced by both clinicians and pathologists in practice. Limited sampling of lung tissue often reflects the "real world" situation encountered in medical-legal consultation where lung resections and tissue processing are often performed externally and the consultant has little control over extent and site of sampling, particularly in tumor resection specimens. In the medicallegal setting, the pathologist is charged with ascertaining the role of asbestos as causative factor in the development of a malignancy. In settings where assessment is limited by the above factors, the pathologist may choose to remain impartial and allow others to argue the clinical evidence for the diagnosis.

\section{Conclusion}

In summary, our findings suggest that the accuracy of a radiographic determination of mild asbestosis in the face of a concomitant history of heavy cigarette smoking should be viewed with skepticism. Whereas an ILO reading of $\geq 1 / 0$ was a reliable indicator of mild interstitial lung disease in the current study, it seems to be one that lacks specificity. Prospective controlled studies will be required in order to determine the accuracy of current clinical criteria for the diagnosis of pulmonary asbestosis in cigarette smokers. In addition, the role of cigarette smoking as the causative factor of interstitial fibrosis should be examined prospectively, and a possible etiologic role for other dusts and fumes excluded by detailed ultrastructural and energy dispersive microprobe analyses.

\section{Disclosure}

Dr Richard L Kradin and Dr David C Christiani have served as expert witnesses in medical-legal cases of asbestos-related 
disease. Dr David C Christiani contributed to the 2004 ATS statement on the diagnosis of nonmalignant diseases related to asbestos. The authors report no other conflicts of interest related to this work.

\section{References}

1. American Thoracic Society. Medical section of the American Lung Association: The diagnosis of nonmalignant diseases related to asbestos. Am Rev Respir Dis. 1986;134(2):363-368.

2. American Thoracic Society. Diagnosis and initial management of nonmalignant diseases related to asbestos. Am J Respir Crit Care Med. 2004;170(6):691-715

3. International Labour Office. Guidelines for the Use of the ILO International Classification of Radiographs of Pneumoconioses: ILO Occupational Safety and Health Series No 22, Revised Edition. Geneva, Switzerland: International Labour Office; 2011.

4. Gamsu G, Salmon CJ, Warnock ML, Blanc PD. CT quantification of interstitial fibrosis in patients with asbestosis: a comparison of two methods. AJR Am J Roentgenol. 1995;164(1):63-68.

5. Roggli VL, Gibbs AR, Attanoos R, et al. Pathology of asbestosis - an update of the diagnostic criteria: report of the asbestosis committee of the college of American Pathologists and Pulmonary Pathology Society. Arch Pathol Lab Med. 2010;134(3):462-480.

6. Hnizdo E, Sluis-Cremer GK. Effect of tobacco smoking on the presence of asbestosis at postmortem and on the reading of irregular opacities on roentgenograms in asbestos-exposed workers. Am Rev Respir Dis. 1988;138(5):1207-1212.

7. Katzenstein AL, Mukhopadhyay S, Zanardi C, Dexter E. Clinically occult interstitial fibrosis in smokers: classification and significance of a surprisingly common finding in lobectomy specimens. Hum Pathol. 2010;41(3):316-325.

8. Washko GR, Hunninghake GM, Fernandez IE, et al; COPDGene Investigators. Lung volumes and emphysema in smokers with interstitial lung abnormalities. N Engl J Med. 2011;364(10):897-906.

9. Craighead JE, Abraham JL, Churg A, et al. The pathology asbestosassociated diseases of the lungs and pleural cavities: diagnostic criteria and proposed grading schema. Report of the Pneumoconiosis Committee of the College of American Pathologists and the National Institute for Occupational Safety and Health. Arch Pathol Lab Med. 1982;106(11):544-596.
10. Tossavainen AR. Asbestos, asbestosis and cancer: the Helsinki Criteria for diagnosis and attribution. Scand J Work Environ Health. 1997;23(4):311-316.

11. Henderson DW, Jones ML, De Klerk N, et al. The diagnosis and attribution of asbestos-related diseases in an Australian context: report of the Adelaide Workshop on Asbestos-Related Diseases. October 6-7, 2000. Int J Occup Environ Health. 2004;10(1):40-46.

12. Yousem SA. Respiratory bronchiolitis-associated interstitial lung disease with fibrosis is a lesion distinct from fibrotic nonspecific interstitial pneumonia: a proposal. Mod Pathol. 2006;19(11):1474-1479.

13. Fraig M, Shreesha U, Savici D, Katzenstein AL. Respiratory bronchiolitis: a clinicopathologic study in current smokers, ex-smokers, and never-smokers. Am J Surg Pathol. 2002;26(5):647-653.

14. Hankinson JL, Odencrantz JR, Fedan KB. Spirometric reference values from a sample of the general US population. Am J Respir Crit Care Med. 1999;159(1):179-187.

15. Ghio AJ, Roggli VL. Diagnosis and initial management of nonmalignant diseases related to asbestos. Am J Respir Crit Care Med. 2005;171(5):527.

16. Zitting AJ, Karjalainen A, Impivaara O, et al. Radiographic small lung opacities and pleural abnormalities in relation to smoking, urbanization status, and occupational asbestos exposure in Finland. J Occup Environ Med. 1996;38(6):602-609.

17. Kipen HM, Lilis R, Suzuki Y, Valciukas JA, Selikoff IJ. Pulmonary fibrosis in asbestos insulation workers with lung cancer: a radiological and histopathological evaluation. Br J Ind Med. 1987;44(2):96-100.

18. Becklake MR. Asbestosis criteria. Arch Pathol Lab Med. 1984; 108(2):93

19. Craighead JE, Abraham JL, Churg A, et al. Asbestosis criteria (in reply). Arch Pathol Lab Med. 1984;108(2):93.

20. Gefter WB, Conant EF. Issues and controversies in the plain-film diagnosis of asbestos-related disorders in the chest. J Thorac Imaging. 1988;3(4):11-28.
International Journal of COPD

\section{Publish your work in this journal}

The International Journal of COPD is an international, peer-reviewed journal of therapeutics and pharmacology focusing on concise rapid reporting of clinical studies and reviews in COPD. Special focus is given to the pathophysiological processes underlying the disease, intervention programs, patient focused education, and self management protocols.

\section{Dovepress}

This journal is indexed on PubMed Central, MedLine and CAS. The manuscript management system is completely online and includes a very quick and fair peer-review system, which is all easy to use. Visit http://www.dovepress.com/testimonials.php to read real quotes from published authors. 